\title{
Taif University Female Golf Transportation Cars Application: Analysis, Design, and Implementation
}

\author{
Yasser A. Nada \\ Department of computer science, \\ Faculty of Computers and \\ Information Technology, \\ Taif University - K S A
}

\begin{abstract}
This paper proposes design and implementation of an android mobile application. This proposed application is used to manage the transportation process of female students in the Taif University at KSA. Moreover, this proposed application assists the females to easily transfer between campus buildings. In addition, it saves time and effort. Furthermore, this proposed application provides excellent services to students and visitors of Taif University. Also, the Golf cars are used and managed by the proposed mobile application. This application uses GPS location system to track the drivers' locations and plot their positions route on the Google maps. Finally, the proposed application is implemented using XAMPP Control Panel V 3.2.1, Java Development Kit, Android Studio 1.5.
\end{abstract}

\section{Keywords}

Golf Cars - Mobile Application - Android - transportation , GPS.

\section{INTRODUCTION}

As a result of the development of new technologies, people now tend to use smart phones in their daily activities, due to the importance of transferring between lectures service at the university using a golf car, there must be some kind of application of the provision of booking cars and arrange a very quick and easy way to suit style student life service. Since students now must wait until one car come by accident, it waited five minutes from two hours, before the car comes, which might cause late to attend lectures and lose marks as well. They do not know how long they have to wait, and they do not know whether there are any more cars today, they do not know if the car is coming full or has a place. It will solve all these problems by using the proposed application in this paper.

Time is a significant factor in people's lives these days, especially the students, and given the importance of the time they have, one of the most urgent needs of those days is to provide time for the students in this paper. To improve the transport facilities which provided Taif University for students to transfer from a lecture to another or from one college to another. Must enhance services to meet the needs of students, especially in the time-saving. Currently students must go out and stand by the street and wait maybe for hours until the car came by chance, so I thought in this paper to resolve this problem, students can drive demand through the phone without having to go abroad and wait for the car, and add more strength to this service we will create an application on the phone to make it more available to everyone who is in need.

Most computer technology focuses on end-users and activities to solve their problem and not a machine. Because of the growing number of students at the University of Taif female special section, this paper was proposed to make life easy for those who are in Taif university study, by suggesting golf mobile auto transport applications. It will be added to many of the functions of the application services.

Golf cars may have been invented as an accessory for a leisurely game, but their usage has been extended far beyond the bounds of the local country club. The market used to consist almost exclusively of large fleet sales to golf courses. Now, the small vehicles are used everywhere, from farms to airports and from warehouses to universities. Golf cars are also being purchased as personal mobility vehicles, an efficient way to get around a neighborhood. Electric Golf cars use a bank of standard lead-acid batteries to run an electric motor. They are designed to be used all day and then recharged all night: at the end of the day, they are plugged into a standard power outlet. Some brands also support "opportunity charging", simply plugging in the cart when they are not in use[1][2].

Due to the increasing number of students at the University of Taif specifically female section, proposed in this paper is to make life easy for those who in the University, it will be to provide excellent services to students and visitors at the University of Taif. Moreover, through the Golf cars transportation mobile application, Many services and functionalities will be added to the application.

The Semantic Web is a web that is able to describe things in a way that computers can understand. In ontology technology classes and their instances are used to describe domain concept specific resources, data properties and object properties are used to describe characteristics of resources and relationships between them [3]. A challenge for the Semantic Web is enabling information interoperability between related but heterogeneous ontology[4].

Mapping or digital cartography is the process by which a collection of data is compiled and formatted into a virtual image. The primary function of this technology is to produce maps that give accurate representations of a particular area, detailing major road arteries and other points of interest. The technology also allows the calculation of distances from once place to another.

Though digital mapping can be found in a variety of computer applications, such as Google Earth, the main use of these maps is with the Global Positioning System, or GPS satellite network, used in standard automotive navigation systems.

\section{RELATED WORKS}

In [5] presented the ComfortDelGro Taxi Booking Application is the ideal taxi booking application for individuals on the go. This user-friendly application offers 
convenience by allowing users to pre-set their favorite locations and journeys for their taxi bookings. It even allows users to book a taxi at their current location, determined by their phones' GPS.

It is an android application that allow the registered and nonregistered people to book a taxi based on their current location using the GPS, so there is no need to enter your location textually, for the signed up users they can book using the address of his / her past bookings, User can mark his or her frequent pickup address as Favorites and use this address for future bookings, the user can check on the status of their booking or cancel it even through an SMS message in Figure (1). This application has easy and user-friendly interface, but the colors and the design are not so attractive.
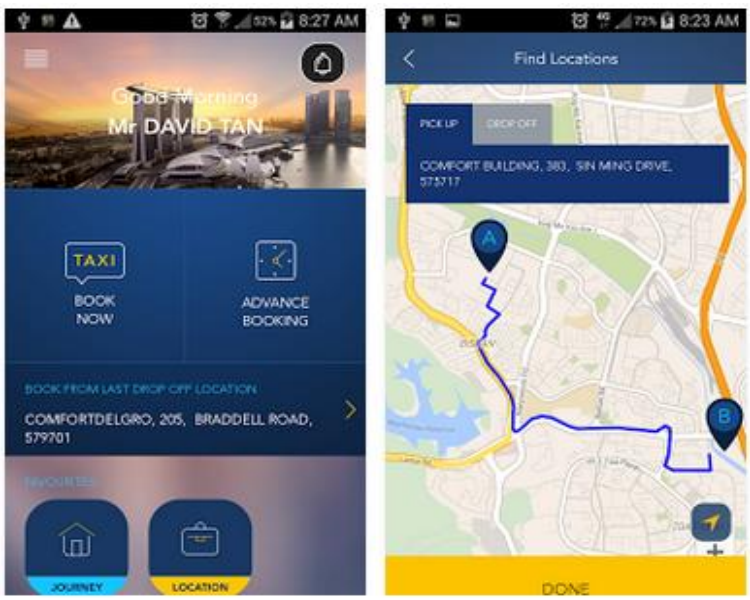

Fig 1: The comfortdelgro taxi booking application

In [6] Book your local taxi companies in two taps with the Taxi Caller Passenger application. With Taxi Caller, you can use your smart phone to book rides with licensed taxi companies in over 40 countries.

This application provides taxi service timeshare interest but does not provide a registration numbers, but to connect to any driver and provide maps to clarify the place of the driver, in Figure (2), but the map is clear and this happened for the application to assess the bad in people of users for this application.
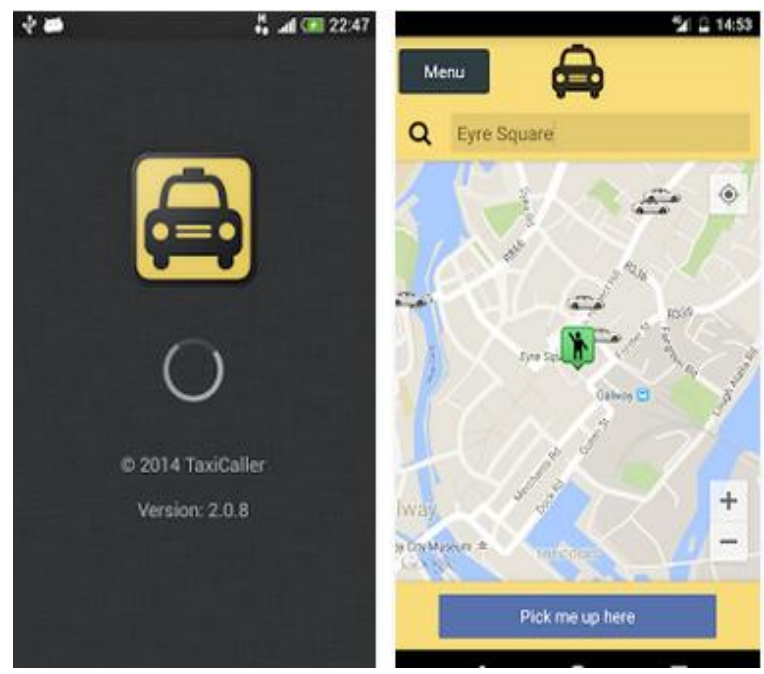

Fig 2: Taxi caller passenger application
This research explores the application of archived data from Automated Data Collection Systems (ADCS) to transport planning with a focus on bus passenger travel behavior, including Origin-Destination (OD) inference, using London as a case study. It demonstrates the feasibility and ease of applying trip-chaining to infer bus passenger OD from smart card transactions and Automatic Vehicle Location (AVL) data and is the first known attempt to validate the results by comparing them with manual passenger survey data[7].

As an alternative transportation paradigm, shared vehicle systems have become increasingly popular in recent years. Shared vehicle systems typically consist of a fleet of vehicles that are used several times each day by different users. One of the main advantages of shared vehicle systems is that they reduce the number of vehicles required to meet total travel demand. An added energy/emissions benefit comes when lowpolluting (e.g., electric) vehicles are used in the system. In order to evaluate operational issues such as vehicle availability, vehicle distribution, and energy management, a unique shared vehicle system computer simulation model has been developed. As an initial case study, the model was applied to a resort community in Southern California[8].

This paper has designed and implemented an intelligent tour planning system capable of 1) selecting TPOIs based on a personalized information rather than per-TPOI preference, 2) generating a tour plan that maximizes the satisfaction degree for a tourist. To reduce the response time resulting from the calculation of $\mathrm{O}(2 \mathrm{n} \cdot \mathrm{n} !)$ complexity, we used initial set reduction, distributed computing via MPI-based Linux cluster, and finally Lin-Kernighan heuristic. An user interface was also implemented on a portable device using the utility of embedded operating system[9].

In this application differs from other applications such as registration in the service also provides maps and directions are clear.

\section{SYSTEM ANALYSIS}

The Merriam-Webster dictionary defines systems analysis as "the process of studying a procedure or business in order to identify its goals and purposes and create systems and procedures that will achieve them in an efficient way". Another view sees systems analysis as a problemsolving technique that decomposes a system into its component pieces for the purpose of the studying how well those component parts work and interact to accomplish their purpose[10].

\subsection{Activity Diagrams}

The administrator has many options after login to the application in Figure (3):

1- Manage students (block or unblock)

2- Manage drivers (add - modify - delete)

3-Manage maps including add or modify or delete maps points. 


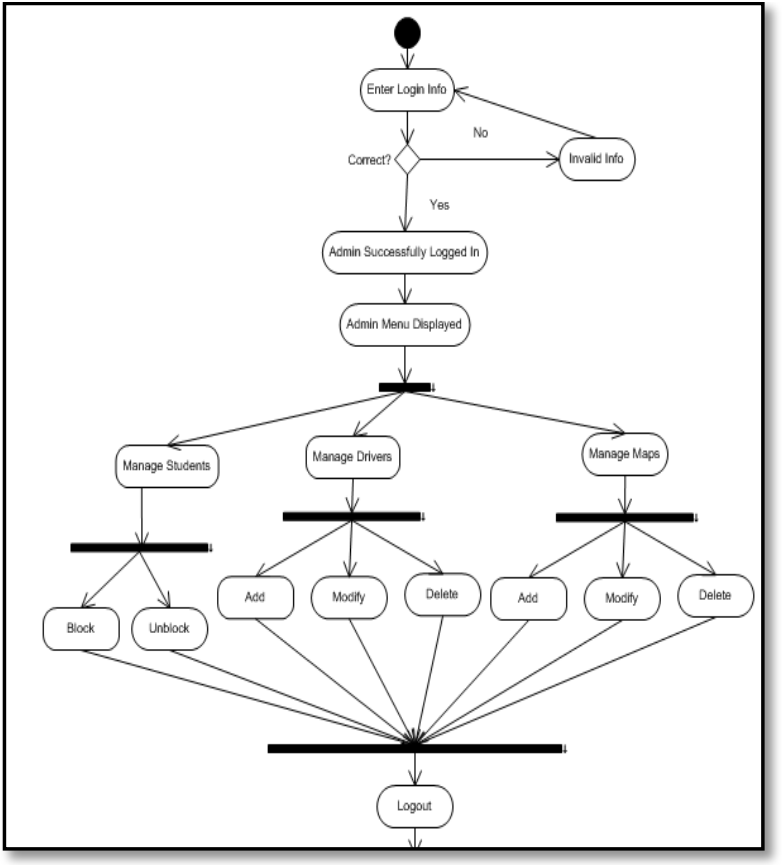

Fig 3: Administrator activity diagram.

Drivers must $\log$ on, and can display the schedule must be followed, stopping at each point and there also can receive alerts from students when they ask where are you? It is on the driver to respond by sending a place of its location and addition, the driver when he finds anything in his car and it must be this thing recorded in the application under the name of research and loss (in Figure 4).

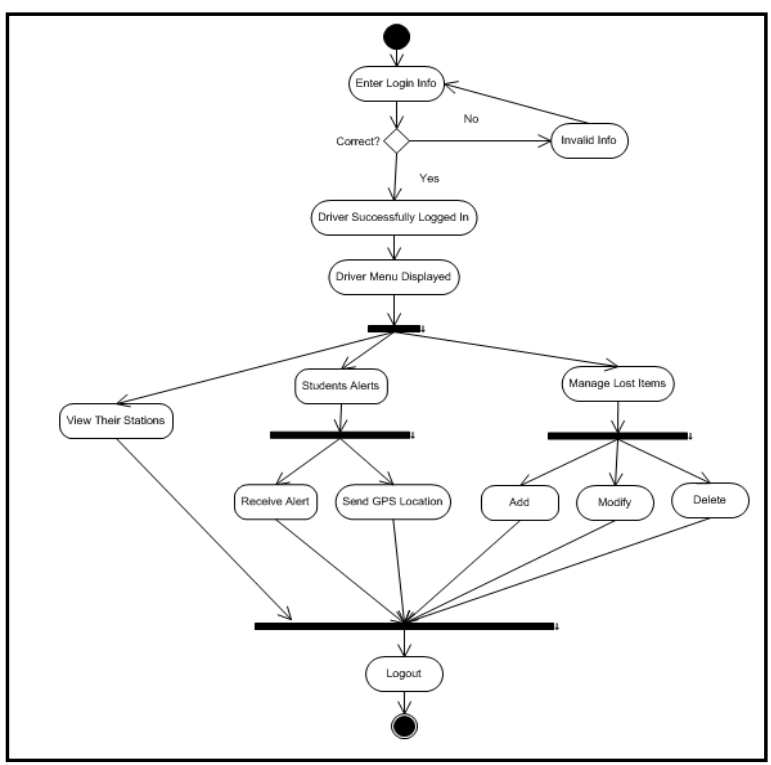

Fig 4: Drivers activity diagram.

The student will have several options in the application he will try to login by the ID and password. she will view all drivers names with information about stop points and pick one from the map to send alert for the driver of this stop point, the alert will be sent with the student GPS, and she will wait from driver reply with his GPS location also plotted on the map to see where she is now(in Figure 5). Students can manage lost and found items.

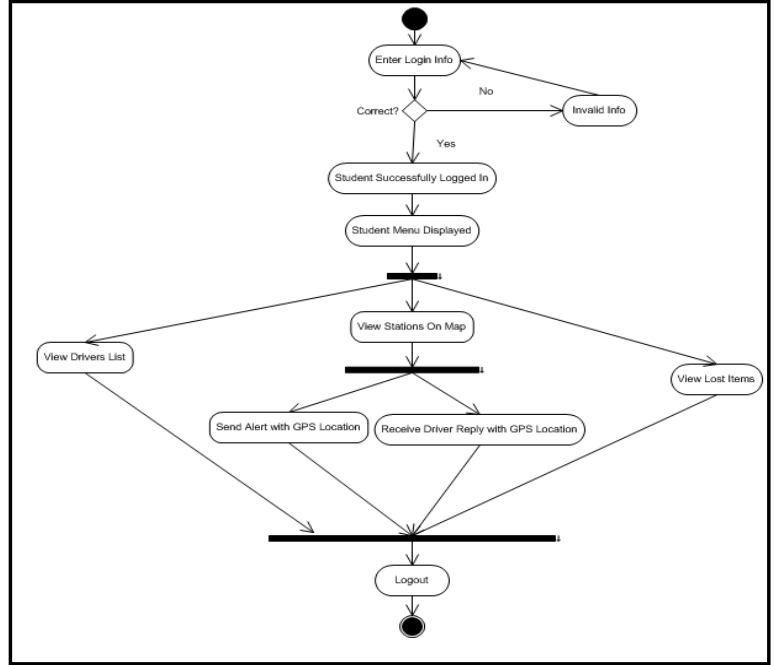

Fig 5: Students activity diagram.

\subsection{ER Diagram}

Called the scheme which we drew upon data base design scheme of relations and links Entity Relationship Diagram and ERD Acronym (in Figure6).

Definitions on the ERD:

- Database object: is mainly table is a table that contains a set of columns and a set of lines

- Metadata attributes: It is all the columns in the table above

- Entity: a collection of metadata attributes that is, it is one of the lines of the previous table.

- Among the entities entity set: The several lines of the previous table together form the entity set

- Restrictions constraints: derived from the information we have obtained

- Link in the relational database: link the table through the same descriptors in it.

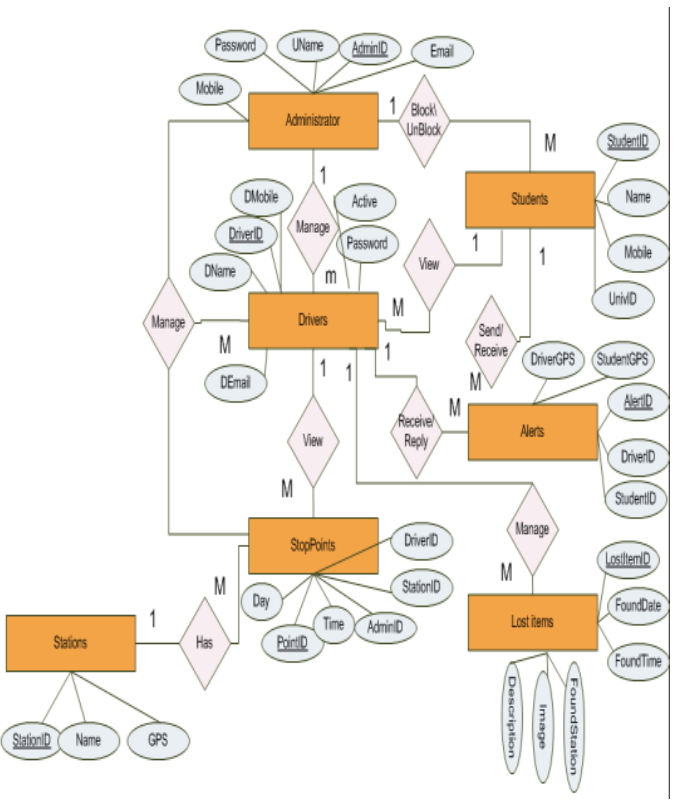

Fig 6: ER Diagram. 


\subsection{Class Diagram}

Here the classes that included in the system, the classes as follows:

Administrator: to store the admin login information

Drivers: to store the drivers' information and personal information and activation status

Students: store the authorized students information and activation status

Lost items is the class in which the drivers add lost item details. Such as date of found, and image and description of the item. Then when anyone came to take the item (owner) the item removed from the database.

Stop points: is the stations' of the map, in which the drivers must stop in which stations. Each stop point must have time and day of the week for each time. And who is the driver and who is the admin who add it.

Stations : is the general locations where the cars must stop for students

Students alerts: each time a student request driver location a signal will be sent and received from the drivers, the GPS signals with the time and sender and receiver all are stored in that class (in Figure 7).

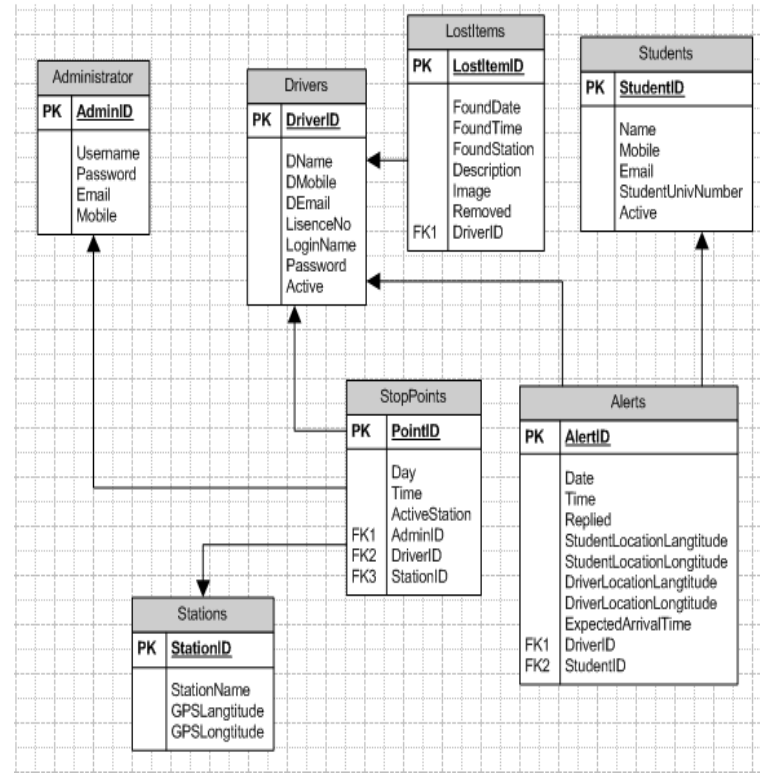

Fig 7: Database schema diagram.

\section{SYSTEMS DESIGN}

One of the most interesting, and most difficult, of the tasks that we may undertake in our careers as engineers or computer scientists is the design of an entire system. A system is a set of interacting parts, generally too large to be built by a single person, created for some particular purpose[11].

The process of defining the architecture, components, modules, interfaces, and data for a system to satisfy specified requirements. Systems design could be seen as the application of systems theory to product development. There is some overlap with the disciplines of systems analysis, systems architecture and systems engineering[12].

\subsection{Logo Design}

I've designed a logo for the work in the beginning.

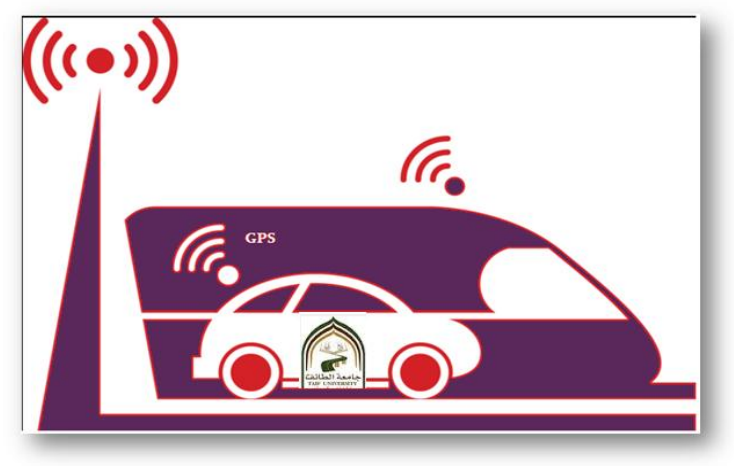

Fig 8: Project logo.

\subsection{Application Interface Design}

\section{Main Login Screen}

This is the main screen of the application, from that screen students can login or admin or driver can chose to login. The login for student by enter their university ID and the password they chose (in Figure 9).

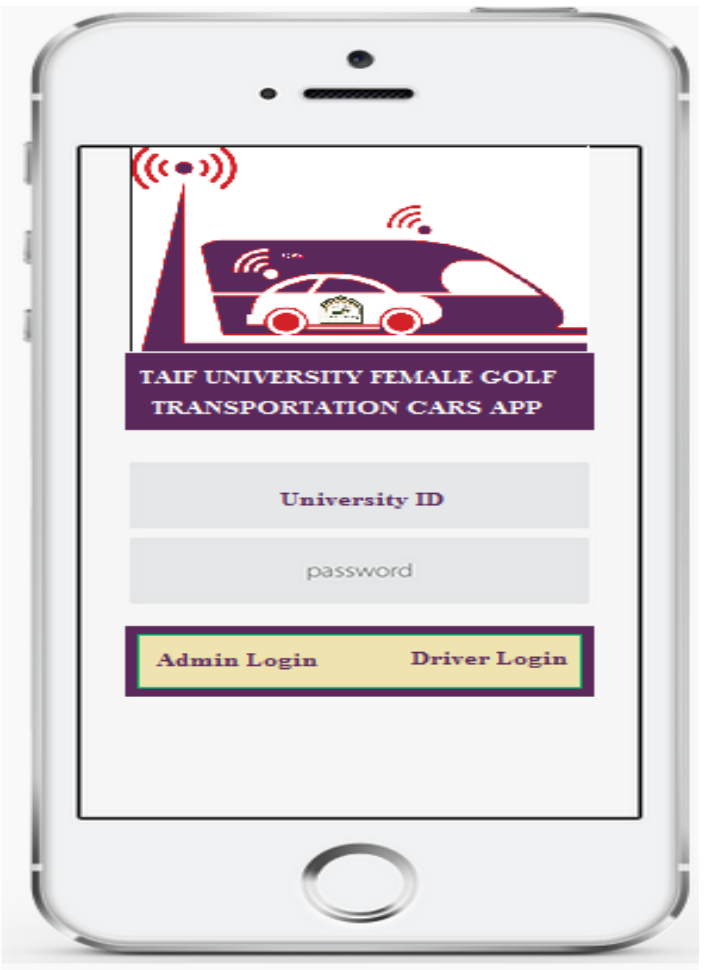

Fig 9: Login screen.

\section{Students Menu Screen}

Here is the main screen of the students after they login, from that menu they have several options(in Figure 10):

Drivers list: students can list all the drivers in the application and view their details

Stop points: the students can view all the names of stop stations that the cars pass on, from these points they can see the drivers and send them signal requests where they are.

Received signals: the driver when reply on any signal, it will notify the student here. 
Lost and found: here the list of the items which drivers found in their cars with their details.

About the application: a help details for the application.

Logout: to logout of his area.

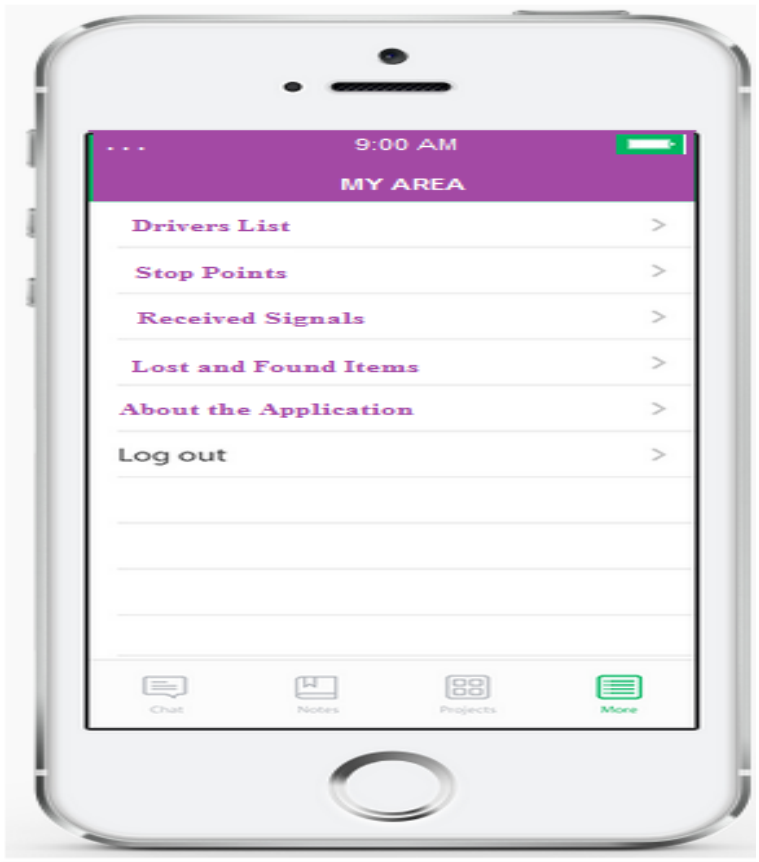

Fig 10: Students menu screen

\section{Students Stop Points Screen}

This is the stop point screen, which show all the stop points and students can send alerts for drivers from it (in Figure11).

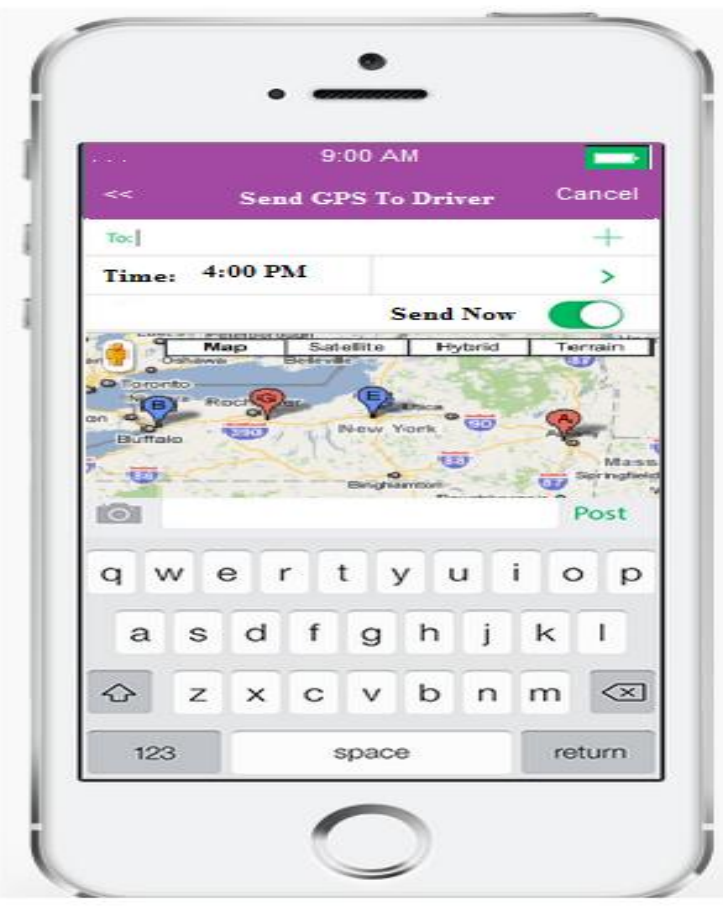

Fig 11: Stop pints screen

\section{IMPLEMENTATION SYSTEM}

In this section, we will deal with the implementation of application, ranging from the design of the database tables, and then use the Android interface design studio, and finally explain all page design and the code in detail.

\subsection{Software Requirements}

In this paper, using many of the tools and programs to implement the database and applications of mobile phone Android. And now the oldest brief description of each language and tools which will be used by in this paper.

\subsubsection{XAMPP Control Panel V 3.2.1}

XAMPP is a free and open source cross-platform web server solution stack package developed by Apache Friends,[13] consisting mainly of the Apache HTTP Server, MariaDB database, and interpreters for scripts written in the PHP and Perl programming languages.[14][15] XAMPP stands for Cross-Platform (X), Apache (A), MariaDB (M), PHP (P) and Perl (P). It is a simple, lightweight Apache distribution that makes it extremely easy for developers to create a local web server for testing and deployment purposes. Everything needed to set up a web server - server application (Apache), database (MariaDB), and scripting language (PHP) - is included in an extractable file. XAMPP is also cross-platform, which means it works equally well on Linux, Mac and Windows. Since most actual web server deployments use the same components as XAMPP, it makes transitioning from a local test server to a live server extremely easy as well.

\subsubsection{Java Development Kit}

Java Platform, Standard Edition (Java SE) lets programmers develop and deploy Java applications on desktops and servers, as well as in today's demanding embedded environments. Java offers the rich user interface, performance, versatility, portability, and security that today's applications require[16].

In this work, I will be programming applications using the Java programming language. Java Development Kit installed because it is required to operate android studio.

\subsubsection{Android Studio 1.5}

Android is an operating system based on the Linux kernel. The project responsible for developing the Android system is called the Android Open Source Project (AOSP) and is primarily lead by Google.

The Android system supports background processing, provides a rich user interface library, supports 2-D and 3-D graphics using the OpenGL-ES (short OpenGL) standard and grants access to the file system as well as an embedded SQLite database.

An Android application typically consists of different visual and non visual components and can reuse components of other applications [17].

For that $\mathrm{i}$ use it in this paper to design the XML layouts (screens) and then program them using java programming languages.

\subsection{Database Implementation}

The database in this paper implemented using phpMyAdmin, it's the server which could host the MySQL database which used through this paper as online database for the golf cars application, Structure of the database tables as follows:

\section{Administrator Table}

This table allow admin to login to the application and manage drivers, stop points and other application contents (in Figure 12). 


\begin{tabular}{|c|c|c|}
\hline 囯 & Browse & Structure \\
\hline & \# Name & Type \\
\hline$\square$ & $1 \underline{\text { AdminID }}$ & $\operatorname{int}(2)$ \\
\hline$\square$ & 2 Username & $\operatorname{varchar}(20) 1$ \\
\hline$\square$ & 3 Password & varchar(20) I \\
\hline$\square$ & 4 Mobile & int(14) \\
\hline$\square$ & 5 Email & $\operatorname{varchar}(50)$ I \\
\hline
\end{tabular}

Fig 12: Administrator table

\subsection{Application Implementation}

The application implemented using android under Java programming, and here we list the main screens and codes as follows:

\section{Main Screen}

This is the main screen of the application; the user must choose an area (student - driver - administrator).

Student can login by enter his university is and password (in Figure 13).
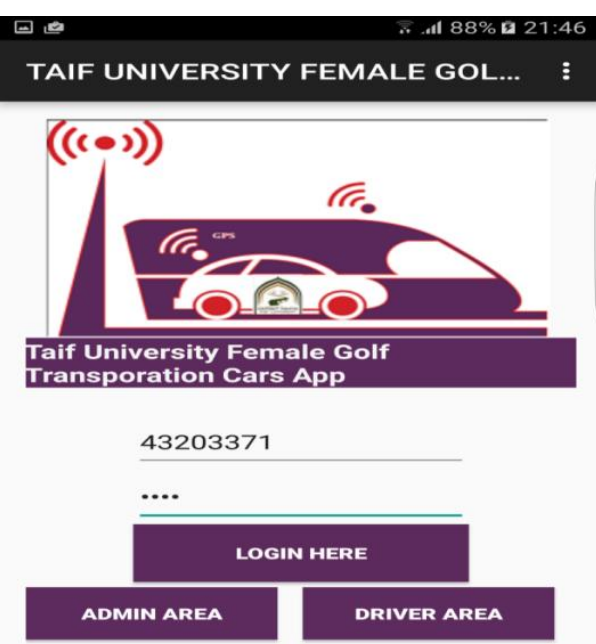

Fig 13: Main screen

\section{Student Area}

After the student login successfully, she can enter her area and browse her menu which has the following options:

View drivers list - view stop points of golf cars - send their alerts to drivers - receive drivers positions - view lost items list (in Figure 14).

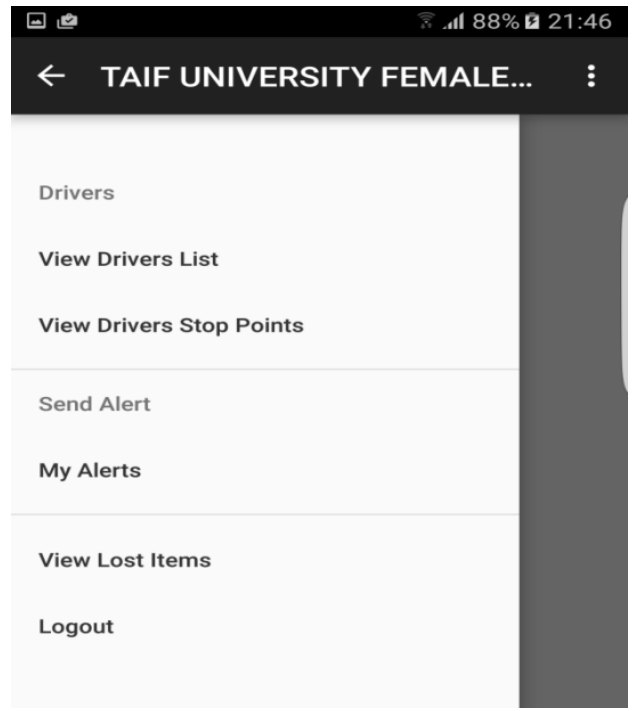

Fig 14: Student menu

\section{Student Area - Driver List}

In this screen the student can view all the drivers list and contact information in order to contact him for any lost item (in Figure 15).

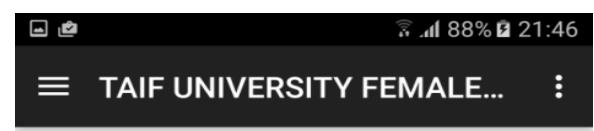

\begin{tabular}{l} 
View Drivers \\
AhmadD \\
info@yahoo.com \\
556765654 \\
12345 \\
\hline Mohammed \\
Zaher \\
info@yahoo.com \\
553265214 \\
123456 \\
\hline Qusai Sharqar \\
in@yy.com \\
552134567 \\
528456 \\
\hline
\end{tabular}

Fig 15: Student view driver

\section{Student Area - View Stop points}

This is the screen of the student to see the drivers schedule, they can see each driver on which day and which time he will be in certain location, the location determined by press the GPS Button number 1. And when the student press the point button (2) her location as an alert will be sent to driver(in Figure 16). 


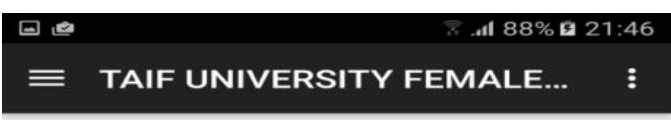

View Stop Points

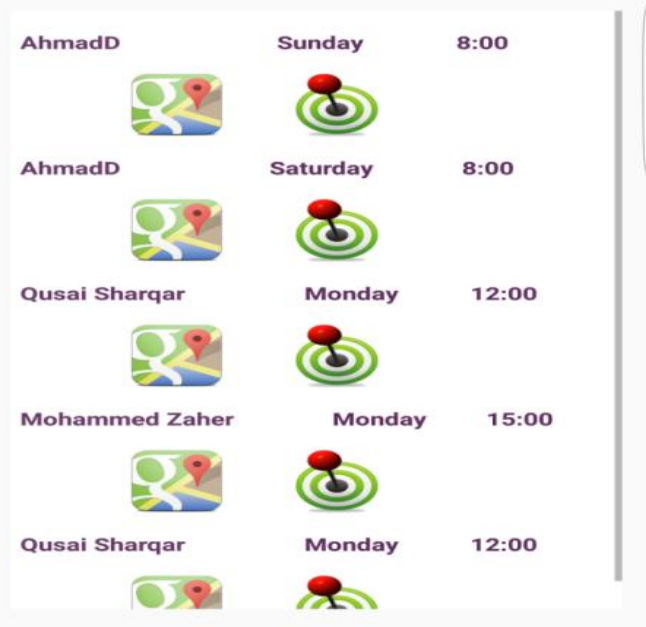

Fig 16: View stop points

\section{Student Area - Driver stop point location on Map}

This is the screen that shows the stop point location on Google maps. We have around 13 stations driver goes around them (in Figure 17).

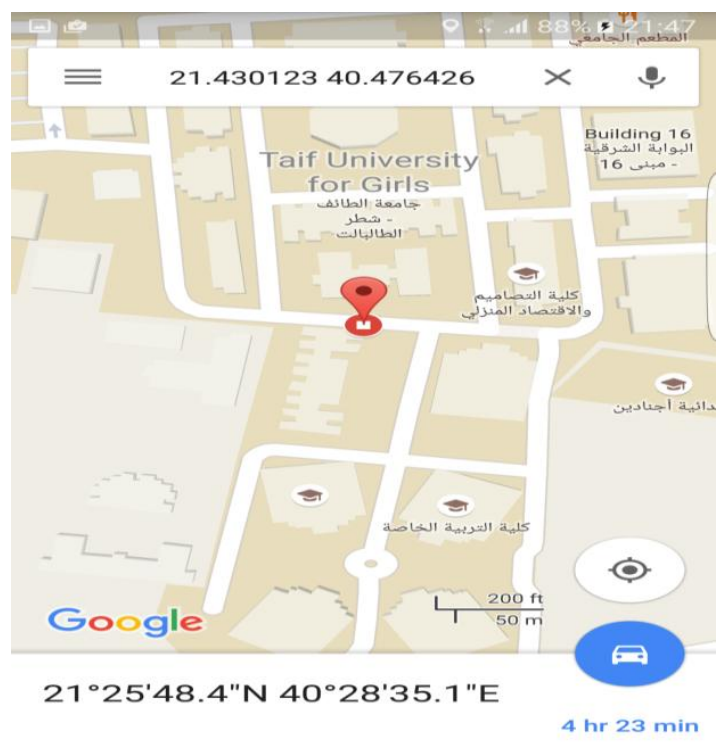

Fig 17: Stop points on map

\section{Student Area - Receive Driver Reply}

This is the screen that shows if the driver reply, if he reply the student will by able to view where is the driver now by press the map (in Figure 18).

\section{曰๒ ๒

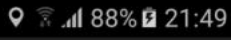 \\ $\equiv$ TAIF UNIVERSITY FEMALE... $\quad$ :}

\section{My Alerts}

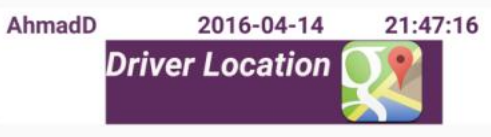

Fig 18: Receive driver location

Administrator login by insert username and password, the code of the login process as follows:

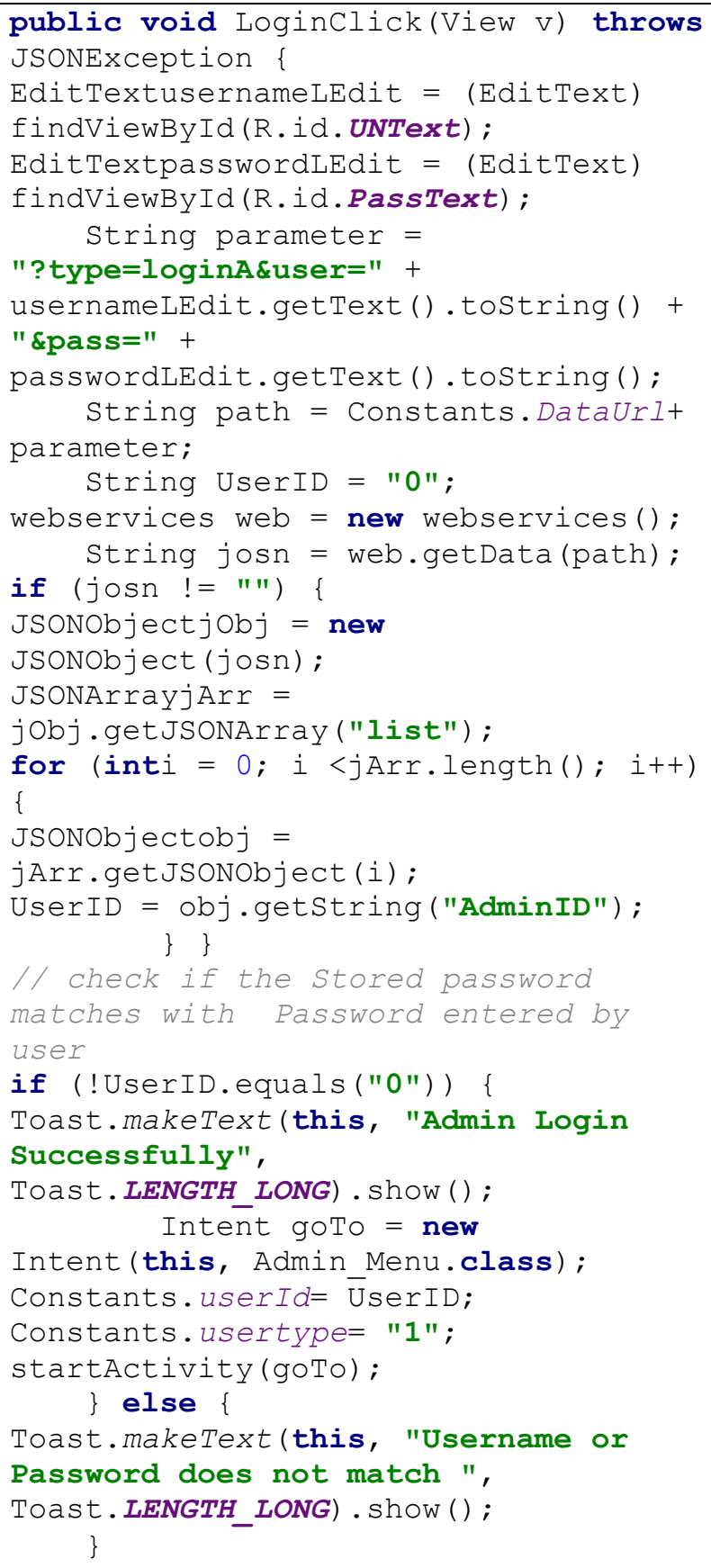




\section{GPS Send Alert Code:}

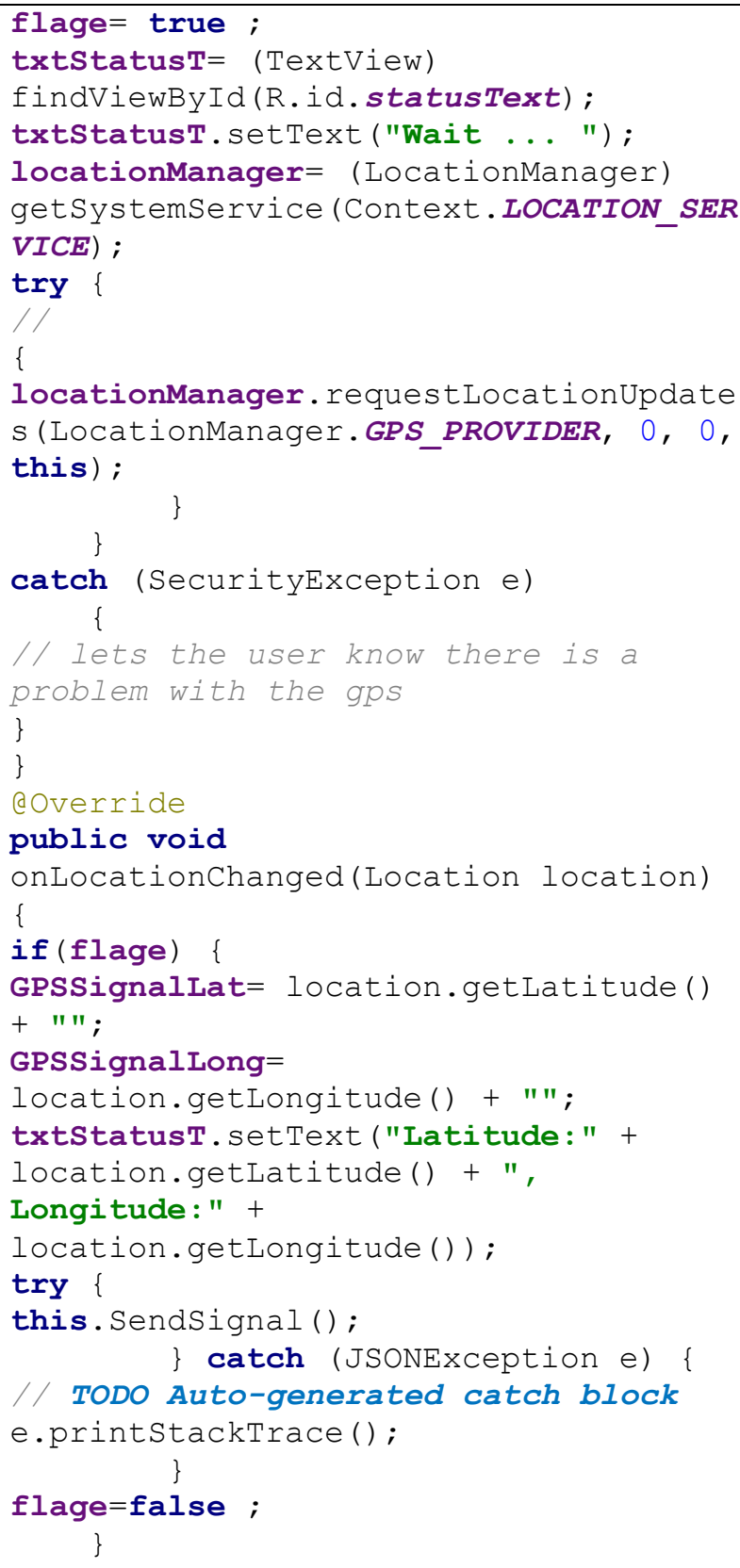

\section{CONCLUSION}

In this paper, a mobile application, which used Android operation system to manage the transportation process in the Taif University, is proposed. This application provided many services such as remote management of transport golf cars using mere finger pressure on a mobile phone. In addition, it comprised a map to show the places from which the golf cars can be accessed. This application provide a current status of each golf car, if it busy or has free seats. Furthermore, this application is used to manage university staff, drivers and maintenance members. Moreover, an effective GPS, which apple to track the drivers' locations and plot their positions route on Google maps, is used.

\section{REFERENCES}

[1] Wenzhong Gao, "Performance Comparison of a Fuel CellBattery Hybrid Power train and a Fuel Cell-Ultracapacitor Hybrid Power train, IEEE TRANSACTIONS ON VEHICULAR TECHNOLOGY, VOL. 54, NO. 3, MAY 2005.

[2] Ultracapacitors Challenge the Battery, Online Available: http://www.worldandi.com, 2004.

[3] Hong Wang, Zhenjie Pan, Wentao Zhou., "The Design and Implementation of Information System in Civil AirportEmergency Management Based on Semantic Web", 25th Chinese Control and Decision Conference (CCDC), IEEE 2013.

[4] Valerie Cross, Xueheng Hu. "Fuzzy Set and Semantic Similarity in Ontology Alignment", WCCI 2012 IEEE World Congress on Computational Intelligence, Brisbane, Australia June, 10-15, 2012.

[5]ComfortDelGro Taxi Booking App. https://play.google.com/store/apps/details?id=com.codigo. comfort.

[6]TaxiCaller,https://play.google.com/store/apps/details? id=com.taxicaller.app.

[7] Wei Wang, John P. Attanucci and Nigel H.M., "Bus Passenger Origin-Destination Estimation and Related Analyses Using Automated Data Collection Systems, Bus Passenger Origin-Destination Estimation and Related Analyses", Journal of Public Transportation, Vol. 14, No. 4, 2011.

[8] Matthew Barth, Michael Todd, "Simulation model performance analysis of a multiple station shared vehicle system", Transportation Research Part C: Emerging Technologies, Volume 7, Issue 4, August 1999, Pages 237-259, 1999.

[9] Junghoon Lee, Euiyoung Kang, Gyung Leen Park, "Design and Implementation of a Tour Planning System for Telematics Users", Volume 4707 of the series Lecture Notes in Computer Science pp 179-189,Computational Science and Its Applications - ICCSA 2007.

[10] Lonnie D. Bentley, "Systems Analysis and Design for the Global Enterprise", 7th Edition, 2007.

[11] Jim Waldo, " On System Design", Sun Microsystems, Inc 1 Network Drive Burlington, Perspectives 2006-6 In an Essay Series Published by Sun Labs December, 2006.

[12] Ulrich \& Eppinger, "Product design \& Development", New York: Irwin McGraw-Hill, 2000.

[13] Kai Seidler, "Interview with Kai Seidler from the XAMPP project", MySQL AB. Retrieved 2015.

[14] apachefriends.org, "New XAMPP with MariaDB", apachefriends.org. 19 October 2015.

[15] Yank Kevin, "PHP \& MYSQL Novice To Ninja", (fifth edition) Melbourn: sitepoint , 2012.

[16] Friesen Jeff, "Java for Android Development", (2nd edition) New York: Apress, 2013. 


\section{AUTHOR PROFILE}

DR. Yasser Ahmed Nada Was born in Ismailia, Egypt, in 1968. He received the BSc degree in pure Mathematics and Computer Sciences in 1989 and MSc degree for his work in computer science in 2003, all from the Faculty of Science, Suez Canal University, Egypt. In 2007, he received his Ph.D. in Computer Science from the Faculty of Science, Suez Canal University, Egypt. From September 2007 until now, he worked as Associate Professor of computer science. Chair, Department of computer science, Faculty of Computers and Information Technology, Taif University, KSA. His research interests include Expert Systems, Artificial Intelligence, Semantic Web, Object Oriented Programming, Computer Vision, and Genetic. 